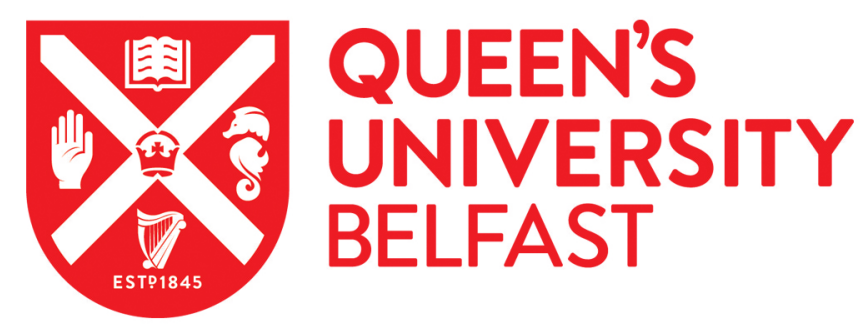

\title{
Triggering BESS Inertial Response with Synchronous Machine Measurements
}

Brogan, P. V., Best, R., Morrow, D., Bradley, C., Rafferty, M., \& Kubik, M. (2018). Triggering BESS Inertial Response with Synchronous Machine Measurements. In 2018 IEEE Power \& Energy Society General Meeting (PESGM): Proceedings (IEEE Power \& Energy Society General Meeting (PESGM): Proceedings). Institute of Electrical and Electronics Engineers Inc.. https://doi.org/10.1109/PESGM.2018.8586499

Published in:

2018 IEEE Power \& Energy Society General Meeting (PESGM): Proceedings

Document Version:

Peer reviewed version

Queen's University Belfast - Research Portal:

Link to publication record in Queen's University Belfast Research Portal

Publisher rights

(c) 2018 IEEE.

This work is made available online in accordance with the publisher's policies. Please refer to any applicable terms of use of the publisher

\section{General rights}

Copyright for the publications made accessible via the Queen's University Belfast Research Portal is retained by the author(s) and / or other copyright owners and it is a condition of accessing these publications that users recognise and abide by the legal requirements associated with these rights.

Take down policy

The Research Portal is Queen's institutional repository that provides access to Queen's research output. Every effort has been made to ensure that content in the Research Portal does not infringe any person's rights, or applicable UK laws. If you discover content in the Research Portal that you believe breaches copyright or violates any law, please contact openaccess@qub.ac.uk. 


\section{Triggering BESS Inertial Response with Synchronous Machine Measurements}

\author{
Paul V. Brogan, Robert Best, \\ D. John Morrow, Cormac Bradley, Mark Rafferty \\ School of Electronic, Electrical Engineering and Computer Science \\ Queens University Belfast, UK \\ paul.brogan@qub.ac.uk
}

\author{
Marek Kubik \\ Market Director \\ AES Energy Storage \\ Amsterdam, Netherlands
}

\begin{abstract}
Synthetic inertia devices must deliver power during maximum RoCoF, which is observed to occur during the first $500 \mathrm{~ms}$ post fault. The use of a droop characteristic with a deadband is demonstrated to be unfit for purpose. The ideal response (with present technologies) is demonstrated to be a maximum power ramp in minimum time post fault. This paper demonstrates a method of rapidly detecting and categorizing under frequency events by monitoring synchronous machines. PMU and point on wave data, sampled at $6.4 \mathrm{kHz}$, from a power station and a laboratory set up, under transient events, is presented. A rapid inertial power ramp signals the onset of the events. Sub-cycle voltage and current variations are demonstrated as a potential method for reliably detecting frequency transients and triggering a synthetic inertia response.
\end{abstract}

\section{INTRODUCTION}

Large continental power systems are unlikely to experience low inertia issues in the near term [1]; but will face them in the medium term if renewable energy targets are met [2]. On smaller networks transmission system operators (TSO) are addressing forthcoming challenges [3] and dealing with near term problems [6]. Ireland has set ambitious renewable energy (RE) targets whereby $40 \%$ of electrical power will be sourced from renewable sources [7], primarily from wind turbines. To achieve this the Irish power system will need to operate at a system non-synchronous penetration (SNSP) of 75\% [8].

Operating at an SNSP of $75 \%$ could result in frequency events becoming 4 times more severe; therefore a $360 \mathrm{mHz} / \mathrm{s}$ frequency event (regularly experienced on the Irish system [9]) could instead result in a $1.44 \mathrm{~Hz} / \mathrm{s}$ event. Events in excess of 0.5 to $1 \mathrm{~Hz} / \mathrm{s}$ have the potential of tripping anti-islanding relays, which would cause cascade tripping of distributed generation, at a time when power systems need them most. EirGrid and SONI (Ireland's TSOs) have years of experience operating a modern power system at SNSPs exceeding $50 \%$, the current operating limit is $60 \%$ and it is planned to increase to $75 \%$ in 2020 [10].

A number of strategies can be employed to securely operate a power system at low inertia, such as, keeping additional plant synchronized at reduced output [11] and limiting the largest single infeed [3]. An additional method is to employ new technologies to replace the inertial power response that

This work was supported by Innovate UK and EPSRC under Grant EP/N508408/1. has been lost by the displacement of synchronous machines. A study published by EirGrid/SONI [6] concludes that $360 \mathrm{MW}$ of battery energy storage (BESS) would permit the Irish system to maintain its present stability.

Work at Queen's University Belfast (QUB) has concluded that $360 M W$ of BESS could replace the response from $3 G W$ of synchronous generation [9], if they respond sufficiently quickly. In this paper a droop response from a BESS is demonstrated to be insufficient for replacing the inertial response of synchronous generators. To replace the inertial response BESS must achieve maximum power deliver during the period of maximum RoCoF. To this end an emergency power ramp, triggered by a emergency ramp signal, seems to be the best method of delivering power during the inertial response window.

This paper investigates a novel method of rapidly and accurately detecting the onset of a frequency transient, ideally in under two cycles. QUB has experience of working with PMU data and fast capture $(6.8 \mathrm{kHz})$ event data from synchronous machines [9]. From experience the best indicator of a frequency transient is a sudden change in power output and this is demonstrated from PMU and point on wave data. In this investigation several under frequency events are initiated on a $7.5 \mathrm{kVA}$ alternator supplying switched loads. Point on wave (fast capture) data are analyzed to determine the beginning of the event rapidly and accurately.

Power system events such as short circuits and synchronisation can cause similar power power changes [4] and these have been studied for some time [5]. Three different types of events were initiated on the laboratory set up, these involved switching a resistive load, an inductive supply line and shunt capacitors. In each case a step change in power output was detected and signaled the start of an event. Point on wave voltage and current measurements demonstrate a method of distinguishing frequency transients over a single cycle.

These preliminary results demonstrate that this method is worth investigating further on other laboratory configurations, computational models and synchronous machine fast captures. This method could be applied to provided enhanced power station functionality, or as part of a wide-area frequency transient detection and distributed response system. 


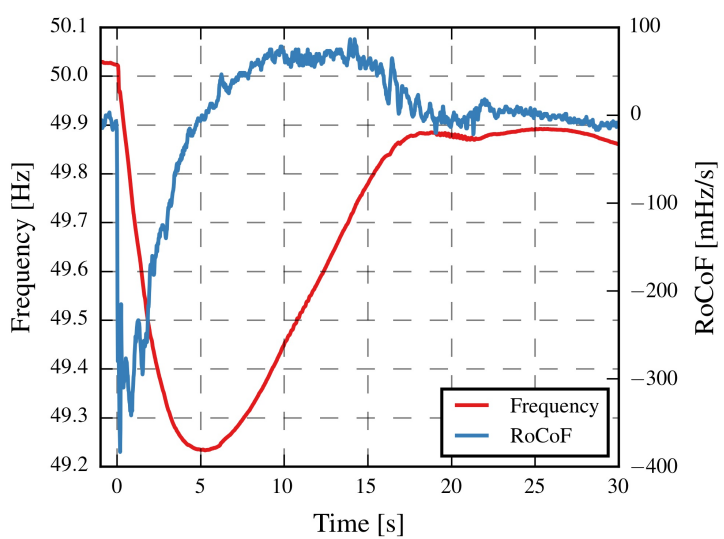

Fig. 1. Plot of frequency and RoCoF on the Irish Power system, recorded on multiple PMUs at generator terminals

\section{Optimal BESS RESPONSE TO FREQUENCY TRANSIENTS}

At present many BESS are operating with a droop characteristic, whereby power output increases with frequency deviation from nominal. A $1 \%$ droop with a 0.05 or $0.1 \mathrm{~Hz}$ deadband is proposed by National Grid in [12]. It is the conclusion of the authors that this type of response has very little impact on RoCoF during a frequency transient and therefore cannot be described as synthetic inertia.

Shown in Fig 1 is a trace of frequency and RoCoF reported by multiple PMUs following the loss of a major generator, in this case it was $430 \mathrm{MW}$, supplying approximately $10 \%$ of demand and representing $14 \%$ of synchronous generation. These types of transients are not uncommon on the Irish system and are representative of a dynamic or low inertia system. It is demonstrated in [1] that larger systems will experience this RoCoF as synchronous generation is displaced by DG.

\section{A. The unsuitability of a droop response}

The property of inertia is measured as an objects resistance to change in motion, therefore maximum power delivery must occur in response to, or during, maximum RoCoF. Maximum RoCoF in Fig 1 can be observed to occur during the first $500 \mathrm{~ms}$. During this event it took $240 \mathrm{~ms}$ for the frequency to reach the droop deadband and a further $1.60 s$ to maximum power delivery at $49.5 \mathrm{~Hz}$. Even a BESS with a perfect droop characteristic would have little impact over the first $500 \mathrm{~ms}$; during this time maximum RoCoF, torque and oscillation excitation occur.

\section{B. The problems with an inertial response}

Displayed in Fig 2 is the ideal per unit inertial response during the event in Fig 1. This type of response is often observed from CCGT plant with no droop response [9].

An inertial response is ideal for reducing RoCoF during the early stages of a frequency transient. Unfortunately, with the inertial response power output drops to zero at the frequency nadir and goes negative during the frequency recovery period.

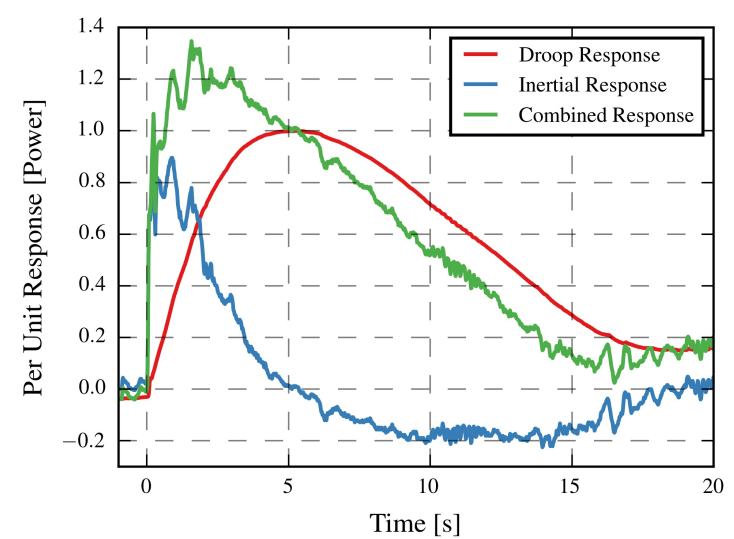

Fig. 2. Ideal power response to the frequency transient in Fig 1

\section{Optimal BESS response during a transient}

The summation of an ideal inertial response and an ideal droop response results in the response plotted in Fig 2, 'Combined Response'. The characteristics of this plot are an initial extremely high ramp, or even step change, in power at the onset of the frequency transient, followed by something of a plateau and a gentle ramp down. An undesirable feature of the plot are the oscillations during the first 4 seconds and in the region of 15 to 20 seconds.

Engineers are usually averse to introducing a step change into power systems, largely due to real fears in regards to exciting harmonic and sub-harmonic oscillations. It is demonstrated in the next section that synchronous machines introduce a power step change in excess of most inverter limits. Further more, existing services utilize a step change in power, including firm frequency response [13] and static reserve provision [11]. The problem with these services is that the emergency response is triggered once a frequency of $49.7 \mathrm{~Hz}$ or $49.5 \mathrm{~Hz}$ is reached (1.06 or $1.84 s$ in Fig 1), far too late to have an effect on maximum RoCoF.

It is proposed that a BESS should respond to a genuine frequency transient by ramping to full power as quickly as possible to alleviate the initially high RoCoF conditions. Maximum power output should be maintained while frequency remains below a certain quantity, as with a $1 \%$ droop characteristic. Once the frequency has returned within predefined limits the BESS may ramp down in accordance with a droop characteristic [6] or remain on if participating in reserve services. It is expected that a BESS would not participate in undesirable frequency oscillations and that it would provide a symmetrical service for over and under frequency events.

The relevant parameters for the proposed BESS operation are illustrated in Fig 3; under the criteria mentioned above the defining characteristics of the device will be delay time $\left(t_{\text {delay }}\right)$ and ramp rate $\left(t_{\text {ramp }}\right)$. The delay time arises from the time taken to positively identify that a frequency transient has taken place plus the time taken to instruct the BESS to operate. In this scenario it is assumed that an emergency ramp has been initiated and that the ramp rate will be determined by 


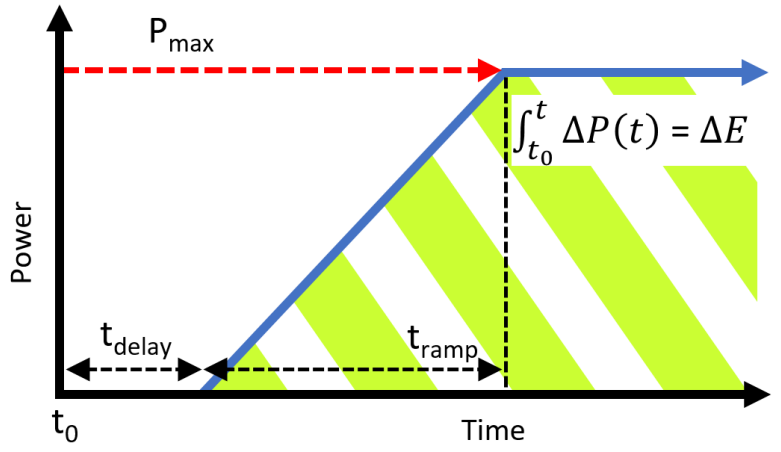

Fig. 3. Characteristics of an inertial BESS response

the maximum inverter ramp, rather than following an external control such as a droop response.

Reducing the ramp time will largely be the responsibility of manufacturers and somewhat determined by technology; either on the inverter side (e.g. thyristor or IGBT) or on the battery side (e.g. super capacitors, lithium ion or flow batteries). If BESS inverters achieve a sufficiently high ramp they may be moderated, as mentioned in [6].

The subject of this paper is reducing the delay time, this involves accurately detecting the onset of an event and categorizing it as a frequency transient. Ideally the detection will be on the order of milliseconds, and the categorization completed on the order of 1 cycle $(20 \mathrm{~ms}$ on a $50 \mathrm{~Hz}$ system, $16.6 \mathrm{~ms}$ on a $60 \mathrm{~Hz}$ system). This is a preliminary investigation and the method will need to be refined for real-time purposes and demonstrated to be extremely reliable, with a minimum of missed events or false positives.

\section{Generator RESPONSE TO TRANSIENTS}

Displayed in Fig 4 is the frequency and power response of a synchronous machine during an under frequency transient, this can be compared to the smaller machines under test conditions in [4] and [5]. The frequency and power reported by a PMU is displayed alongside the power output estimated from point on wave data. The PMU employed also has a digital fault recorder (DFR) feature that is triggered under specified conditions. The PMU GPS time synchronization, along with the DFR being in the same unit, allows the time series to be accurately aligned.

From tests carried out in QUB it is known that there is a characteristic delay in PMU frequency estimation of 40 to $60 \mathrm{~ms}$. The $60 \mathrm{~ms}$ delay in frequency estimate is evident in Fig 4, but the delay in estimating the PMU power is 20 to $40 \mathrm{~ms}$. In research into frequency transients within QUB the change in PMU power, created by an increase in the current phasor magnitude, has proved to be the most reliable indication of the onset of a frequency transient.

The point on wave power plot, shown in Fig 4, is produced by simply multiplying the line current by the phase voltage recorded by the DFR. The sampling rate of the DFR is 128 samples per cycle (on a $50 \mathrm{~Hz}$ system) or $6.4 \mathrm{kHz}$. This type of real-time monitoring and calculation can easily be executed on development boards, such as Arduinos.

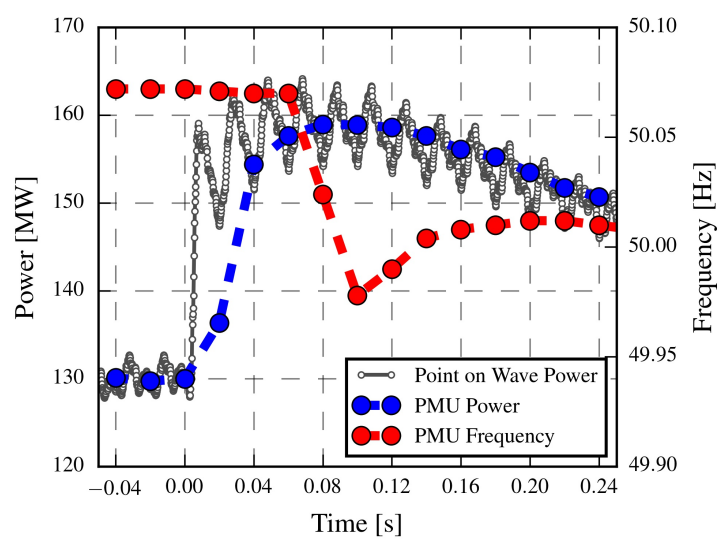

Fig. 4. Plot of PMU frequency and power during an under frequency transient, note time difference between point on wave and PMU estimated power

The oscillation in the estimate of the power from the point on wave measurements is characteristic of monitored synchronous generators; and the lab setup studied in this section. The oscillation can arise from system imbalance and machine parameters, but are not investigated further. This oscillation could limit the speed of detection of a power swing, as the power output must exceed a threshold greater than the observed background oscillations.

Under the circumstances presented in Fig 4 the peak to peak power oscillation is in the region of $4 \mathrm{MW}$. During the inertial power swing the power output rises by $25 \mathrm{MW}$ in less than 20 samples $(3.125 \mathrm{~ms})$, this is a ramp of $8 \mathrm{GW} / \mathrm{s}$. If this type of estimate can be used to reliably detect and classify frequency transients, before triggering a large BESS response, then it could go a long way to significantly improving grid security.

\section{A. Laboratory Investigation of Frequency Transients}

QUB has a power lab with a $7.5 \mathrm{kVA}$ three phase cylindrical alternators driven by DC machines that can be loaded in a variety of ways and has been used in previous tests [4]. In this setup a frequency transient was induced by switching in load using a three phase switched load bank (Fig 5a). To test the reliability of the detection method a switched induction bank (simulating transmission line switching) was operated in series with the load (Fig 5b) and separately a switched capacitor bank was operated in parallel with the load (Fig 5c).

A sudden loss of generation was simulated by switching in an additional resistive load. The voltage, current and power changes can be observed in Fig 6. The change in voltage and current are presented in volts and amps (rather than per unit) as the scales happen to be similar and show the characteristics of the changes. The variations in generator output that resulted from the switching events are presented in Table I.

An under frequency transient will evolve differently on the lab setup versus a power system over many cycles (100 $\mathrm{ms}+$ ); however, the simulation should accurately recreate the conditions experienced during the first few cycles $(0-40 \mathrm{~ms})$ post fault. The power response in Fig 6 can be compared to Fig 4 


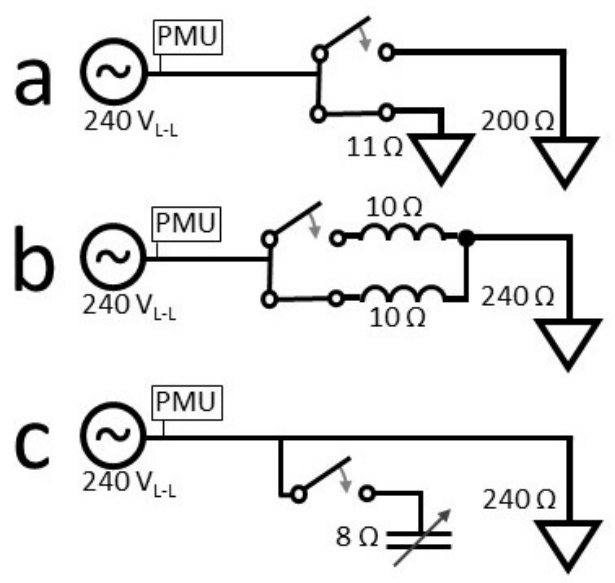

Fig. 5. Single line diagram of lab setup, (a) resistive load switching, (b) transmission line loss/gain and (c) shunt capacitor switching

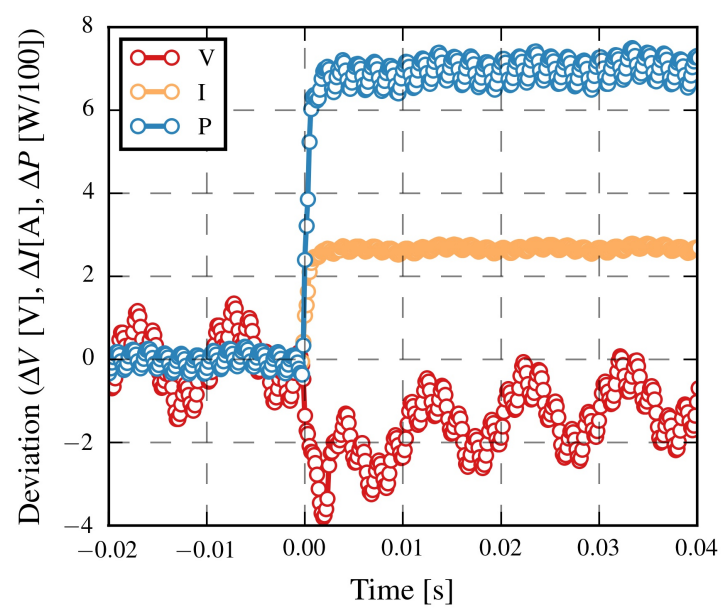

Fig. 6. Point on wave measurements during resistive load switching

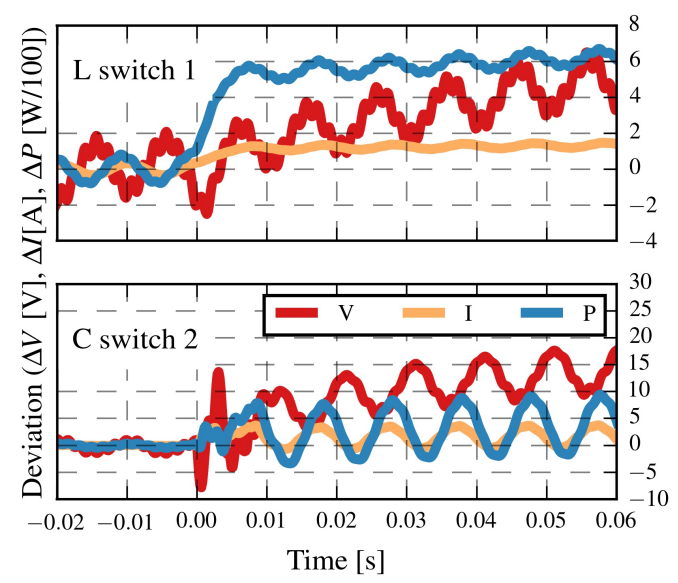

Fig. 7. Point on wave measurements during transmission line and shunt capacitor switching

for similarities in point on wave power. Generators are connected to loads through transmission lines that can be switched
TABLE I

DETAILS OF THE TRANSIENTS STUDIED ON A $7.5 \mathrm{kV} A$ ALTERNATOR

\begin{tabular}{ccccc}
\hline $\begin{array}{c}\text { Operation } \\
\text { Label }\end{array}$ & $\begin{array}{c}\text { Initial } \\
\text { Power [kW] }\end{array}$ & $\begin{array}{c}\text { Peak } \\
\text { Power [kW] }\end{array}$ & $\begin{array}{c}\text { Power } \\
\text { Difference [W] }\end{array}$ & $\begin{array}{c}\text { Change } \\
{[\%]}\end{array}$ \\
\hline R Switch 1 & 2.76 & 3.07 & 310 & 11.2 \\
R Switch 2 & 1.47 & 2.19 & 720 & 49.0 \\
R Switch 3 & 2.08 & 3.44 & 1,360 & 65.4 \\
L Switch 1 & 2.77 & 3.38 & 610 & 22.0 \\
L Switch 2 & 2.61 & 3.38 & 770 & 29.5 \\
C Switch 1 & 3.56 & 3.90 & 340 & 9.55 \\
C Switch 2 & 3.20 & 3.70 & 500 & 15.6 \\
\hline
\end{tabular}

in and out under scheduled and unscheduled conditions. When a transmission line is switched in the impedance between the generator and load drops suddenly, drawing more power from the generator. The reduction in impedance will initially cause an increase in the current magnitude, similar to an under frequency transient, this can be observed in Fig 7.

Shunt capacitor banks are switched in and out to raise and lower grid voltage, through the provision of reactive power. During these events significant transient voltage changes can occur and voltage dependent loads draw more power. The voltage perturbations, caused by capacitor switching, are largely smoothed in Fig 7.

\section{ANALYSIS OF RESULTS}

The problem of detecting a frequency transient can be split into two operations, event detection and event categorization. The inertial power response from the synchronous machine was well suited to detecting the start of a frequent event; however, other situations can also result in actual or misinterpreted power ramps. Event detection is based on detecting an exception in power output. Event characterization is based on analyzing the changes in voltage and current during the first cycle post fault.

The switching events were captured by the DFR functions of the PMU, these provided three phase, time-series measurements or voltage and current. In post processing the time series voltage and current measurements were converted to root mean square values and the power was calculated by multiplying the phase voltages by the respective line currents.

\section{A. Event detection}

Detecting the onset of the events was easy given the strength of the signal. The events occurred $200-350 \mathrm{~ms}$ or $1280-2240$ measurements into the file, the first 1000 values were presampled and the peak to peak variation identified; the first point that exceeded the variation by $200 \%$ was set as $t=0$. This method correctly identified the beginning of every event.

\section{B. Frequency transient detection}

If voltage and current measurements were required to differentiate frequency transients from other events. As power is derived from voltage and current it was felt it might not add new information to the classification process. Plotted in Fig 8 


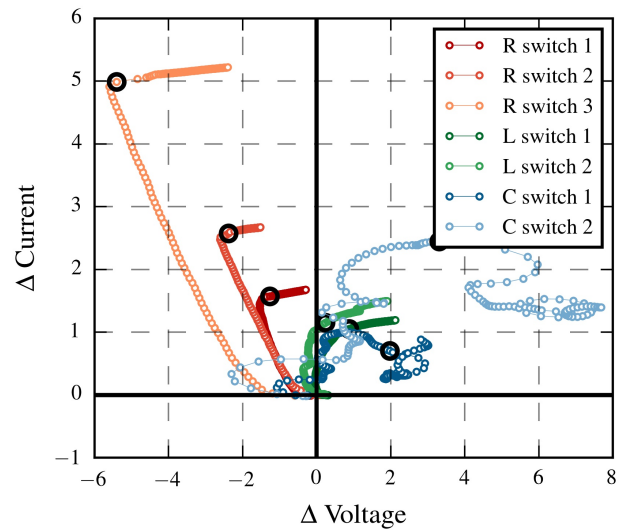

Fig. 8. Plot of voltage and current deviation from initial values, over the first cycle $(20 \mathrm{~ms})$ post event

is the evolution of the 6 events detailed in Table I; all events begin at the origin and migrate outward as the event unfolds. Fig 8 only shows the first cycle, $20 \mathrm{~ms}$ of the event and the results have been smoothed over 64 points, or half a cycle. This smoothing gave optimal differentiation between tests and the points are averaged over the previous 64 measurements and as such reflect what a real-time controller would be interpreting.

The load addition tests clearly have features that distinguish them from the transmission line and capacitor switching tests. A first point of note is that they initially deviate from the origin at an angle of approximately $30^{\circ}$ to the positive y-axis. During this time voltage is falling linearly and current is rising linearly. If this feature can be uniquely attributed to generation loss events, then it could permit event detection in the 2 to 10 $m s$ range.

A second feature of the load change in Fig 8 is the sharp knee point that consistently occurred $10 \mathrm{~ms}$ after event detection. At the knee point the rise in current suddenly slows substantially and voltage begins to recover significantly. The positive identification of this knee point could serve as a detection technique that might require 10 to $15 \mathrm{~ms}$.

A third observation is that the angle between the path taken during the first $10 \mathrm{~ms}$ of the fault and the path over 10 to 20 $\mathrm{ms}$ post fault are both very linear (after the $10 \mathrm{~ms}$ smoothing) and have a consistent angle between them. A technique that verified linearity and angle could determine the start of an event within 15 to $25 \mathrm{~ms}$.

A final point to note is that over the $20 \mathrm{~ms}$ presented in Fig 8 on the resistive load tests remained in the top left quadrant of the plot, this can be defined as $\Delta V<0$ and $\Delta I>0$. Load Change $1(11.2 \%)$ crossed the y-axis after $25 \mathrm{~ms}$, while both Load Change 2 (49.0\%) and Load Change $3(65.4 \%)$ approached the y-axis but never crossed it.

\section{CONCLusion}

It is demonstrated that devices purporting to offer a synthetic inertia service must be able to operate and reach full power in the region of tens to hundreds of milliseconds; for this reason a droop response is wholly unsuited. In order for a synthetic inertia device to operate it must first reliably detect the onset of a frequency transient, ideally in less than one cycle.

This paper has demonstrated that a point on wave $(6.8 \mathrm{kHz})$ measurement of power from a synchronous machine is a reliable method of detecting an under frequency transient. It was also demonstrated that inductive and capacitive switching operations can be mistaken for a frequency event. After event detection, event classification becomes important. A boundary method of event classification has been investigated and significant features highlighted. If these features are unique to frequency transients then they could be employed for subcycle event detection.

One application of this technology is at power stations that wish to increase revenue from enhanced service provision whereby they augment the inertial response of their existing machines. If the frequency transient detection method was networked across many sites, back to a central control, then a highly reliable frequency transient system could be created. The latency inherent in communication networks would add tens to hundreds of milliseconds to the delay in operation, but would allow for a distributed inertial response.

\section{ACKNOWLEDGMENT}

The authors would like to thank AES Energy Storage, AES UK \& Ireland, Eirgrid/SONI, The Northern Ireland Utility Regulator, and Northern Ireland Electricity for their valuable input and Innovate UK for their financial support.

\section{REFERENCES}

[1] Ulbig, Andreas and Borsche, Theodor S and Andersson, Göran Impact of low rotational inertia on power system stability and operation. IFAC Proceedings Volumes, vol. 47, no. 3, pp. 7290-7297, 2014

[2] European Commission 2020 climate \& energy package. https://ec.europa. eu/clima/policies/strategies/2020 en, October, 2017

[3] National Grid System Needs and Product Strategy. June, 2017

[4] R. J. Best and D. J. Morrow and P. A. Crossley, Current transients in the small salient-pole alternator during sudden short-circuit and synchronisation events, IET Electr. Power Appl., 2010, 4, (9), pp. 687700

[5] C. E. Tindall and J. P. Martin and D. J. Morrow and P. A. J. Calvert Transient characteristics of small salient-pole alternators , IEEE Trans., EC-11, No. 3, 1996, pp, 539-546.

[6] EirGrid/SONI RoCoF Alternative \& Complementary Solutions Project Phase 2 Study Report. March, 2016

[7] seai, Sustainable Energy Authority of Ireland Renewable Electricity in Ireland 2015. 2016 Report

[8] EirGrid DS3 Programme Operational Capability Outlook 2016. May 2016

[9] P.V. Brogan , A.H. Alikhanzadeh, R. J. Best , D. J. Morrow , M. L. Kubik Fast Frequency Response Requirements for Replacement of Observed Generator Response During Under Frequency Transients. cigré Symposium Dublin May 2016

[10] EirGrid/SONI DS3 Programme Operational Capability Outlook 2016. May, 2016

[11] EirGrid/SONI Harmonised Ancillary Services Consultation. Tariff Year $1^{\text {st }}$ October 2015 to $30^{\text {th }}$ September 2016

[12] National Grid. Enhanced frequency response; 2016. Available: http://www2.nationalgrid.com/Enhanced-Frequency-Response.aspx.

[13] National Grid. Firm frequency response; 2016. Available: http://www2.nationalgrid.com/uk/services/balancing-services/frequencyresponse/firm-frequency-response/ 